\title{
Educação de jovens e adultos: Movimento de Educação de Base em Tefé, Amazonas (1963/1980)
}

Leni Rodrigues Coelho' ${ }^{1}$ Cristiane da Silveira ${ }^{2}$

\section{Resumo}

Este artigo investiga a trajetória e as ações do Movimento de Educação de Base (MEB) no município de Tefé, no Amazonas. O viver amazônico é peculiar. Neste contexto, o MEB instrumentalizou ações efetivas no campo da educação, da saúde e da organização política, construindo uma importante página na história da educação popular no estado. Para além desse fato, procurou-se compreender o MEB como um movimento organizado pela Igreja Católica com o envolvimento de vários sujeitos: os monitores, os coordenadores e os alunos. As trajetórias e as ações do MEB foram construídas a partir da busca de uma perspectiva crítica e politizadora. O trabalho foi fundamentado por meio de um referencial teórico específico, documentos oficiais e história oral, que possibilitaram a investigação empírica.

\section{Palavras-chave}

MEB. Movimento Social. Educação de Jovens e Adultos.

1. Mestre em Educação pela Universidade Federal de Uberlândia, professora assistente na Universidade do Estado do Amazonas. E-mail: lenicoelho@yahoo.com.br.

2. Doutora em História Social pela Pontifícia Universidade Católica de São Paulo, professora assistente da Universidade do Estado do Amazonas. E-mail: silcristiane@yahoo.com.br. 


\title{
Young and adults education: Education Movement Base in Tefé, Amazonas (1963/1980)
}

Leni Rodrigues Coelho*, Cristiane da Silveira**

\begin{abstract}
This article investigates the trajectory and actions of the Education Movement Base (MEB) in the Tefé Town, in Amazonas. Amazon life is particular. Given the circumstances, MEB used as instruments effective actions concerning education, health and policy organization areas, building an important moment in popular education history in Amazonas. Therefore, we tried to understand the MEB as an organized movement by the Catholic Church involving many subjects, monitors, coordinators and students. The trajectories and the MEB actions were built from the search for a critical and politicizing perspective. The work was grounded by specific theoretical base, official documents and oral history that enabled empirical research.
\end{abstract}

\section{Keywords}

MEB. Social Movement. Youth and Adult Education.

\footnotetext{
* Master in Education at the Federal University of Uberlândia, assistant professor at State Universty of Amazonas. E-mail: lenicoelho@yahoo.com.br.

**Doctor in Social History at the Pontifical Catholic University of São Paulo, assistant professor at State Universty of Amazonas. E-mail: silcristiane@yahoo.com.br.
} 


\section{Introdução}

O Movimento de Educação de Base (MEB) foi criado, em âmbito nacional, no ano de 1961, para atuar em regiões subdesenvolvidas do nordeste, norte e centro-oeste do país. O MEB resultou do convênio entre a Conferência Nacional dos Bispos do Brasil (CNBB) e da União. Naquele momento, a CNBB elaborou um plano de movimento educativo, com base no Decreto 50.370, de 21 de março de 1961, para desenvolver um programa de educação de base, por meio de escolas radiofônicas, junto à população menos favorecida em áreas subdesenvolvidas. O Governo Federal, além de conceder canais radiofônicos aos bispos, autorizou, ainda, a contratação de funcionários federaispara prestaçãodeserviçosnomovimento.

A partir destas escolas radiofônicas, o MEB ofereceu ao público rural, oportunidades de alfabetização, além de proporcionar uma base políticamaisampla, instigandoohomemdocampo a se conscientizar sobre sua realidade e a buscar mecanismos para melhores condições de vida.

Segundo Paiva (2009, p. 61), o MEB tinha como objetivo:

Cooperar na formação integral de adultos e adolescentes, nas áreas subdesenvolvidas do país, e propiciar elementos para que essas camadas da população tomasse consciência de sua dignidade de criatura humana, transformando-se em agente do processo de mudança da realidade em que vivia.

É importante ressaltar que o MEB, em suas práticas pedagógicas, objetivava a conscientização do homem por meio de motivações, mudanças de atitudes e, principalmente, o cooperativismo. A partir desses métodos, buscava-se trabalhar a prática da leitura e da escrita, valendo-se do próprio cotidiano dos alunos para tornar as aulas instrumentos de produção de conhecimento. O MEB implantou projetos e metodologias envolvendo clubes, cooperativas, sindicatos e organizações políticas, tudo em busca de uma educação com maior qualidade (WANDERLEY, 1984). Nesse sentido, percebe-se que o Movimento representou a primeira dimensão profissional da Ação Católica em âmbito nacional, contribuindo, principalmente, para a educação de jovens e adultos no Brasil. Naquele contexto, era elevado o índice de analfabetismo no país, fato considerado uma "vergonha nacional" sendo, então, necessário, erradicá-lo.

De acordo com Fávero (2006), de todos os movimentos de cunho social, o MEB foi o único que logrou de forma mais intensa para o meio rural, inclusive dando apoioà sindicalização rural, sobrevivendo ao golpe de 1964 e à repressão dos anos seguintes. No entanto, o MEB só se tornou possível porque a ação colocou-se no mesmo patamar dos outros movimentos de educação e cultura popular do início dos anos de 1960.

A história do MEB, na região norte, caminhou juntamente com o processo de instauração da Ditadura Militar e visou à alfabetização e à ampliação dos direitos políticos dos sujeitos pertencentes às classes populares. Já a Ditadura, cerceou ações da sociedade civil em detrimento de seus interesses políticos e ideológicos. De acordo com Raposo (1985), a Ditadura Militar não apenas minou perspectivas de ações políticas, como também aguçou o controle ideológico da hierarquia sobre os vários movimentos - o MEB, o sindicalismo rural, a ação católica - candentes naquele momento.

O Movimento de Educação de Base, em Tefé, foi criado em 1o de janeiro de 1963 e desenvolvido por Dom Joaquim de Lange, na época bispo do município. Ao chegar à cidade, em 1947, Dom Joaquim percebeu a imensa extensão territorial e a realidade de exploração, isolamento e pobreza em que se encontravam os ribeirinhos. Após constatar essas condições vivenciadas pela população 
não assistida pelo poder público e pela organização civil, o bispo sentiu-se mobilizado pela situação de descaso em que se encontrava a população do município naquele momento. Dom Joaquim, motivado pela experiência adquirida em sua viagem à Colômbia, implantou a Rádio Educação Rural em Tefé.

Em relaçãoà criação de emissoras católicas, De Kadt (2007) afirma que a obtenção de uma emissora de rádio ia além do projeto educacional, representava prestígio e influência para os bispos, além de incluir, em sua programação, o ensino religioso e a propagação da fé cristã.

A trajetória do MEB, em Tefé, foi singular, pois o Movimento conseguiu resistir ao crescente controle do Estado para com as ações dos movimentos sociais. Se, primeiramente, as ações do MEB se desenvolveram em uma perspectiva crítica e política, baseada nos princípios de Paulo Freire, com o intensificar da repressão política, foi necessário rever, em um segundo momento, suas ações didático-pedagógicas. Para a manutenção do Movimento, em Tefé, foi realizada parceria com o Movimento Brasileiro de Alfabetização (MOBRAL), programa do governo voltado para a educação de jovens e adultos, em uma perspectiva de alfabetizar para inserir o sujeito no mercado de trabalho e também diminuir os altos índices de analfabetismo no país. Nesse sentido, Fávero (2006) afirma que a redefinição dos objetivos e da metodologia do MEB se fez em função de uma nova opção ideológica. Somado a essa questão, De Kadt (2007) salienta que, no auge da ditadura, o MEB atuou muito mais na perspectiva de catequização do que de conscientização.

Além da parceria firmada com o MOBRAL, o MEB, em Tefé, também buscou apoio de instituições como o Banco do Brasil, o Projeto Rondon e a EMATER (Empresa de Assistência Técnica e Extensão Rural) para qualificar e estimular as famílias ribeirinhas na busca de uma melhor qualidade de vida. Nesse sentido, o excoordenador do MEB, Depoente A, afirma que:
O MEB em Tefé tinha apoio da EMATER, que atuava junto aos produtores rurais, ensinando a técnica de agricultura. Esses técnicos davam palestras e faziam acompanhamento das atividades desenvolvidas pelos comunitários, duas vezes por mês faziam esse trabalho. O Banco do Brasil colocou à disposição do MEB um técnico que ia às comunidades, estimulando empréstimos e também verificando a aplicação desses recursos durante a execução dos projetos. Reuniam os beneficiários e davam orientações sistemáticas de como conseguirem recursos junto à instituição. A Promotoria de Justiça acompanhava as reuniões comunitárias de como os cidadãos deveriam conseguir seus documentos de casamento, de registro civil e registro de terras. Já o Projeto Rondon, que tinha na equipe professores, paramédicos e assistentes sociais, fazia as reuniões nas comunidades junto com o MEB, orientando os monitores, as mães e dando assistência à saúde.

No que tange à parceria no âmbito da saúde pública, verificou-se que o MEB trabalhava junto à Secretaria de Saúde do município de Tefé, a fim de qualificar os agentes de saúde para atender o povo ribeirinho em suas necessidades mais imediatas. Após o treinamento, esses agentes recebiam uma caixa com produtos de primeiros socorros para atuarem nas comunidades. De acordo com o ex-coordenador do MEB, Depoente A, os componentes da equipe de saúde:

Levavam cartazes, panfletos e remédios para os moradores das comunidades. O agente de esporte era encarregado de organizar o campo de futebol e treinar os atletas. $\mathrm{O}$ agente pastoral recebia o material da Paróquia que era usado durante a missa aos domingos e dias santos e todos os domingos tinha missa radiofônica. Os agentes recebiam treinamentos no Seminário São José, uma vez por mês para fazerem o atendimento nas comunidades.

Dessa forma, percebe-se que o MEB, em Tefé, atuava não apenas no campo educacional, 
mas também realizava ações em busca da efetiva transformação do contexto em que estava inserido o povo ribeirinho, uma vez que propiciava desde o incentivo e a orientação para empréstimo bancário até a qualificação para a atuação na agricultura. Não menos importante foi a sua contribuição na área da saúde. Tais ações indicam a relevância do movimento para a região do Médio Solimões, já que não ficavam circunscritas ao âmbito educacional.

\section{As ações do MEB em Tefé por meio das aulas radiofônicas}

Um olhar mais aguçado sobre as ações pedagógicas do MEB, em Tefé, revela singularidades importantes para se compreender a sua história. Ressalta-se que a cidade está localizada no interior do Estado do Amazonas, cenário geográfico marcado por grandes extensões territoriais, entremeados por florestas, rios e lagos, o que dificulta a mobilidade, a interação e o acesso à educação formal dos povos ribeirinhos. A partir desse cenário é que se pode compreender a importância das ações do MEB por meio das aulas radiofônicas.

De acordo com Paiva (2009, p. 51), a implantação de emissoras radiofônicas nesse contexto:

Encurtava distâncias, facilitando o acesso dos camponeses à educação, dando-lhes possibilidades de se desenvolverem enquanto membros de uma comunidade maior. $\mathrm{O}$ rádio significava, de forma concreta, a tecnologia a serviço da educação do homem campesino. Era um rádio de ondas cativas, mas, ondas que levavam o camponês a se sentir importante, a tomar conhecimento do que acontecia no seu estado, na sua região, no seu país e no mundo.

Para Peixoto Filho (2003), os programas radiofônicos tiveram papel importante na ação educativa do MEB, uma vez que foi estruturada uma programação educativa intensa, diversificada, motivadora e transmitida em horários diferenciados, atingindo várias faixas etárias da população. No que tange ao âmbito regional e/ou local, percebe-se que as aulas radiofônicas ministradas pelo MEB, na Rádio Educação Rural de Tefé, que funcionava em um primeiro momento no Seminário São José, transmitia cursos de parteiras, primeiros socorros, catequese, esporte, arte e tecelagem. Dessa forma, verificou-se que o MEB, em Tefé, atuou e incentivou a população ribeirinha em diferentes áreas, conforme aponta seu ex-coordenador (Depoente A), incluindo

O desenvolvimento da agricultura, já que era o único recurso do município. Na área de esportes, incentivamos também o artesanato, que já tinha desaparecido aqui na região. Tinham duas pessoas daqui de Tefé que trabalhavam com cerâmica, talas e madeira, então pegamos essas pessoas e treinamos para ensinar os nossos monitores de artesanato. $\mathrm{E}$, com isso, conseguimos devolver o que já tinha desaparecido. Já o esporte envolvia toda a comunidade. Chegou-se a preparar os campeonatos intermunicipais, primeiro o intercomunitário, uma comunidade contra a outra e depois intermunicipais e trouxemos de Manaus os times. O outro foi o folclore: trabalhou-se a cultura popular. Nós conseguimos, no período do folclore, trazer para cá de 80 até 120 cordões de folclore do interior e daqui da cidade. A apresentação era feita na praça da igreja. Nós fizemos também o dia da festa de Tefé que não era celebrado, tinha no documento, mas não era celebrado.

Referindo-se às condições físicas das escolas radiofônicas, Wanderley (1984) afirma que estavam longe de atingir os requisitos mínimos pré-estabelecidos para o funcionamento de uma escola, pois o local era iluminado à luz de lamparina e, na maioria das vezes, as aulas eram oferecidas nas casas dos monitores, em alpendres, terreiros ou latadas. No entanto, tal precariedade não foi suficiente para colocar em risco o trabalho desenvolvido 
pelo MEB. Vale ressaltar que no município de Tefé, assim como na região do Médio Solimões, as condições físicas das escolas não se diferem das descritas em âmbito nacional, uma vez que, ao se pensar nessas escolas não se pode ter em mente uma estrutura formal de educação, pois, na precariedade em que trabalhava o MEB, locais que poderiam ser considerados inapropriados transformavam-se em espaços de aprendizagem.

De acordo com a ex-professora do MEB, Depoente B, as dificuldades encontradas no processo didático-pedagógico aconteciam em detrimento

Do pouco material didático, pois não era suficiente, às vezes tinha dificuldade para fazer trabalho em sala de aula e à distância, porque a gente viajava de canoa para ir dar aula e os alunos para estudar. Alguns moravam perto da própria escola, no mesmo povoado, outros vinham do outro lado do rio e às vezes a chuva e a falta de transporte dificultavam o acesso dos alunos às aulas.

As dificuldades enfrentadas pelos professores e alunos do MEB eram diversas. Ao analisar as entrevistas realizadas com os sujeitos envolvidos, percebe-se, em suas falas, que os problemas eram recorrentes. Nesse sentido, a afirmativa de Pessoa (2002) reforça as condições existentes. A escola não tinha prédio próprio, as aulas eram ministradas na residência do monitor. Faltava, também, material escolar, apostilas, cartilhas e mobiliário. No início do projeto, os monitores não recebiam salário, apenas uma gratificação pelos serviços prestados. Essas dificuldades não foram empecilhos para impedir o trabalho da equipe, que contribuiu para a alfabetização dos ribeirinhos que viviam em total abandono, esquecidos pelo poder público.

Para a realização das aulas radiofônicas, havia uma equipe do MEB (coordenadores e professores) responsável pela elaboração da programação das atividades desenvolvidas: scripts, avisos, convites, melodias e lições. A programação era repassada aos monitores de cada comunidade e destes para a população ribeirinha. Nesse sentido, o excoordenador do MEB, Depoente A, revela que:

O MEB mantinha, em cada localidade, uma sala de aula para alfabetização de jovens e adultos. De 15 em 15 dias, os supervisores faziam a fiscalização nas comunidades. O supervisor chegava, fazia reunião com a comunidade para debater e corrigir as falhas que haviam no trabalho desenvolvido pelo monitor daquela comunidade. Nessas reuniões eram discutidos os problemas da comunidade e possíveis soluções para resolver tais problemas. Após essa fiscalização era redigido e apresentado um relatório com assuntos discutidos na reunião para a coordenação do MEB.

Ao analisar a fala do ex-coordenador do MEB, identificam-se características importantes sobre o fazer pedagógico, pois este era fruto das discussões realizadas entre os sujeitos envolvidos, o que permitia maior envolvimento na busca de soluções para os problemas que afetavam o povo ribeirinho. Nesse processo de reflexão e de amadurecimento de ideias, fazia-se presente estratégias para a conscientização do homem, possibilitando, assim, o acesso à educação nos locais mais longínquos do Médio Solimões.

\section{As singularidades do fazer pedagógico do MEB/Tefé}

Os professores que atuavam no MEB, em Tefé, não possuíam formação específica para a área de alfabetização de jovens e adultos. No entanto, verificou-se que eram oferecidos cursos de treinamento com o objetivo de qualificá-los para atuar em sala de aula. Dessa forma, os coordenadores e supervisores proporcionavam aos monitores orientação e formação continuada para que estes adquirissem conhecimentos e habilidades para alfabetizar seus alunos.

Os professores/monitores do Movimento 
de Educação de Base pertenciam às comunidades enão dispunham de muitos recursos para elaborar suas atividades escolares e ministrar as aulas. De acordo com a Depoente B, ex-professora do MEB, os alunos e monitores enfrentavam, em seu cotidiano, as seguintes dificuldades:

Falta de energia; os alunos tinham vontade de aprender, vinham todas as noites, enfrentavam viagens de canoa, por morarem longe da comunidade; os alunos que moravam próximos levavam seus tambores, cadeira de suas casas para se sentarem, pois não tínhamos cadeiras para todos. O fascínio pela novidade e a vontade de aprender a ler e escrever fazia com que após um dia inteiro de trabalho braçal, os trabalhadores e trabalhadoras tivessem ânimo para acompanhar as aulas que eram ministradas a noite pelos monitores de cada comunidade.

Se, por um lado, as adversidades eram múltiplas e iam desde a infraestrutura até o material didático pedagógico, por outro lado, é perceptível, na fala da professora, o entusiasmo dos sujeitos envolvidos nas ações do MEB. Tais adversidades, na maioria das vezes, eram vencidas por causa da constante preocupação em qualificar os professores/ monitores, considerados fundamentais no desenvolvimento das ações do Movimento.

Os treinamentos oferecidos aos professores/monitores eram organizados pela equipe do MEB e se davam no sentido de auxiliá-los e/ou orientá-los na condução dos alunos em sala de aula. No que se refere aos locais de treinamento, a exprofessora do MEB, Depoente C, afirma que:

A princípio era na sede. Traziam-se todos para cá para a missão, era onde tinha o Centro de Treinamento. Aí, passava uma semana, ou dez dias ou o tempo que era previsto. Com o passar do tempo, as comunidades foram se estruturando e depois foram fazendo casas comunitárias e, onde estava organizada, a gente passou a fazer esse treinamento por região. Então, a gente reunia os monitores por região e levava-os para aquele determinado local onde era combinado e avisava pelo rádio. No São Paulo do Coraci, a gente já tinha uma casa comunitária grande, então treinava o pessoal daquela região lá mesmo. Então foi assim, a princípio tudo era em Tefé, depois foi adotado um sistema de treinar também nas comunidades.

Em relação ao treinamento de supervisores, verificou-se que estes foram orientados e treinados para diagnosticar a realidade das comunidades, no intuito de fazer levantamento da área, para, assim, verificar a viabilidade da instalação de uma escola em cada comunidade. Após a realização da pesquisa, eram escolhidos, pela comunidade, o professor, o líder esportivo, o líder de trabalho comunitário, a liderança no clube de mães, o agente de saúde e da pastoral. Essas pessoas eram, posteriormente, capacitadas em cursos realizadas no Centro de Treinamento da Missão.

Além do diagnóstico, os supervisores tinham também a função de visitar periodicamente as escolas para verificar as dificuldades enfrentadas pelos monitores e alunos, a fim de auxiliá-los em suas atividades escolares e melhorar a qualidade de vida do povo ribeirinho. Segundo a Depoente C, o supervisor tinha como atribuição:

Visitar as comunidades e ajudar na documentação da comunidade; verificar se aquela comunidade queria o estatuto ou o registro do cartório; tirar o CNPJ, o que realmente ela estava precisando. Então, a gente trabalhava com essa questão da organização e ver como poderia ser possível melhorar. Na escola, a gente supervisionava para ver os trabalhos dos monitores e como era que estava o desempenho dos alunos. Em algumas comunidades, trabalhavam com o clube de mães e dentre essas mães o que estavam querendo ou precisando. Todo ano a gente tinha feira de artesanato na festa de Santa Tereza no mês de outubro, então preparávamos as pessoas que iam trabalhar com argila, com tecelagem, tapetes e costuras 
para serem vendidos durante o evento.

Portanto, cabia aos supervisores fazer o acompanhamento nas escolas, nos cadernos dos alunos, verificar o trabalho dos agentes de saúde, bem como visitar os moradores. Após esta visita, era realizada uma reunião com a comunidade para sondar o desempenho do professor/monitor e o cumprimento de seu trabalho. Depois da reunião, redigia-se um relatório, a ser encaminhado ao coordenador do MEB, no qual se apresentavam as dificuldades enfrentadas pela comunidade.

De acordo com Fávero (2006), a supervisão era entendida pelo MEB como processo técnico, voltado, em primeiro lugar, para a escola e para os monitores, rejeitando-se, assim, o caráter de fiscalização e de prestação de contas. Insistia-se na ajuda, no atendimento ao monitor e no auxílio à comunidade. Seus objetivos eram: realizar uma observação das condições materiais da escola e do desempenho do monitor, verificar a adequação e o aproveitamento das aulas e investigar os interesses e as necessidades locais, tendo em vista a possibilidade de solucionar os problemas existentes nos diferentes contextos escolares.

Em relação aos coordenadores do MEB, em Tefé, verificou-se que estes eram preparados em cursos realizados em Manaus, no estado do Pará e na região nordeste do país. O coordenador do MEB de Tefé era quem participava desses cursos e, ao retornar para o seu município, socializava o conhecimento adquirido com os demais membros das equipes da sede em Tefé, Carauari, Fonte Boa e Jutaí. A preocupação central do Movimento era formar uma equipe bem preparada para atuar nas comunidades ribeirinhas, pois disso dependia o sucesso das ações que seriam desenvolvidas nas comunidades. De acordo com Pessoa (2002, p. 122), em Tefé, o Movimento de Educação de Base, antes de colocar em prática suas atividades, preocupou-se em qualificar seus funcionários.
Em 1963, no mês de agosto, organizou-se uma equipe de sete funcionários do MEB que já tinham recebido treinamento no Rio de Janeiro, em Belém, Aracajú, Natal, Bragança, Santarém e Manaus. Daí em diante, no mês de setembro de 1963, o MEB iniciou suas atividades.

\section{Considerações Finais}

Ao analisar os dados documentais que fundamentaram essa pesquisa, verificouse que, apesar do MEB ter repensado sua ação pedagógica no período da Ditadura Militar, seu trabalho, em termos gerais, foi significativo para a região do Médio Solimões, já que propiciou mudanças substanciais no cotidiano vivenciado pelo povo ribeirinho.

O MEB, juntamente com instituições governamentais e não governamentais, contribuíram no âmbito da educação, da saúde, da cultura e do lazer, proporcionando ao povo ribeirinho conhecimentos para atuarem como sujeitos ativos e participativos no contexto em que estavam inseridos.

Um olhar atento para a história de quarenta anos de atuação do MEB, em Tefé, permite afirmar que este foi um movimento educacional e social de grande relevância para o município e a região. O Movimento possibilitou, ao longo da sua existência, a conscientização, a alfabetização e a catequização de centenas de sujeitos pertencentes às classes populares.

Nesse sentido, acredita-se que o Departamento do MEB/Tefé cumpriu com sua função pedagógica, já que se constituiu em experiência inovadora na maior parte do tempo em que atuou no município. As atividades pedagógicas desenvolvidas foram essenciais para que sua ação educativa transcorresse de forma satisfatória e, apesar das grandes dificuldades encontradas, o Movimento proporcionou uma educação diferenciada a partir da realidade do aluno, na busca de uma sociedade mais justa e mais humana. 


\section{Referências}

FÁVERO, O. Uma pedagogia da participação popular: análise da prática pedagógica do MEB Movimento de Educação de Base (1961-1966). Campinas: Autores Associados, 2006.

DE KADT, E. Católicos radicais no Brasil. Brasília: UNESCO/MEC, 2007.

PAIVA, M. M. de (Org.). As escolas radiofônicas de Natal: uma história construída por muitos (1958-1966). Brasília: Liber Livro; Natal: Editora da UFRN, 2009.

PEIXOTO FILHO, J. P. A travessia do popular na contradança da educação. Goiânia: Editora da Universidade Católica de Goiás, 2003.

PESSOA, P. L. História da Missão de Santa Teresa D'Avila dos Tupebas. Manaus: Novo Tempo, 2002.

RAPOSO, M. das G. B. Movimento de Educação de Base: discurso e prática (1961-1967). São Luís: Universidade Federal do Maranhão; Secretaria de Educação do Estado do Maranhão, 1985.

WANDERLEY, L. E. Educar para transformar: educação popular, Igreja Católica e política no Movimento de Educação de Base. Petrópolis: Vozes, 1984.

Submetido em 10 de julho de 2012.

Aprovado em 6 de dezembro de 2012. 